\title{
EFFICIENCY AND PRODUCTIVITY CHANGE ACROSS THE ECONOMIC SECTORS IN LITHUANIA (2000-2010): THE DEA-MULTIMOORA APPROACH
}

\author{
Tomas BALEŽENTIS ${ }^{a}$, Algimantas MISIŪNAS ${ }^{b}$, Alvydas BALEŽENTIS ${ }^{c}$ \\ ${ }^{a}$ Lithuanian Institute of Agrarian Economics, V. Kudirkos g. 18, 03105 Vilnius, Lithuania \\ ${ }^{b}$ Vilnius University, Sauletekio al. 9, 10222 Vilnius, Lithuania \\ 'Mykolas Romeris University, Valakupiu g. 5, 10101 Vilnius, Lithuania
}

Received 15 May 2012; accepted 09 September 2012

\begin{abstract}
Reasonable strategic management requires the complex assessment of the regulated area. This study, thus, presents a multi-criteria framework for frontier assessment of efficiency and productivity across the Lithuanian economic sectors throughout 2000-2010. The data envelopment analysis was employed to estimate efficiency in terms of an output indicator (value added) and input indicators (intermediate consumption, capital consumption, and remunerations). Furthermore, the decomposition of the Malmquist productivity index enabled to describe the impact of frontier shifts and catch-up effect on the overall change in efficiency. The multi-criteria decision making method MULTIMOORA aggregated different indicators of efficiency and productivity and thus resulted in the ranking of the economic sectors. The analysis suggests that services sector was the most efficient one, whereas manufacturing was second best. Certain branches of manufacturing, namely pharmaceutical, wood, food, and furniture industry, were rather efficient.
\end{abstract}

Keywords: efficiency, productivity change, Malmquist productivity index, MULTIMOORA.

Reference to this paper should be made as follows: Baležentis, T.; Misiūnas, A.; Baležentis, A. 2013. Efficiency and productivity change across the economic sectors in Lithuania (2000-2010): the DEA-MULTIMOORA approach, Technological and Economic Development of Economy 19 (Supplement 1): S191-S213.

JEL Classification: C44, C61, D24, M21.

\section{Introduction}

Productivity is considered as the key factor for competitiveness in the long run (European Commission 2011). Indeed, it also guarantees non-inflatory growth and thus provides a 
momentum for increase in real income. It is due to Latruffe (2010) that measures of competitiveness can be broadly classified into neoclassical ones and strategic management ones. The neoclassical approach analyses competitiveness from the viewpoint of international trade flows, whereas the strategic management theories focus on the specific factors of competitiveness. These factors encompass, for instance, profitability, productivity, and efficiency. It is, therefore, important to analyse the trends in productivity and efficiency in order to make reasonable strategic management decisions. Furthermore, this study will focus on the strategic management approach rather than neoclassical one.

One can speak of efficiency when comparing the actual level of productivity with the yardstick one. In case one knows the foremost, ideal goal of production, he can speak of effectiveness, albeit it does seldom occur in the real life. The measurement of efficiency, therefore, involves the benchmarking practice. The relative measurement of efficiency - benchmarking - is an important issue for both private and public decision makers to ensure the sustainable change. It is due to Jack and Boone (2009) that benchmarking might create motivation for change; provide a vision for what an organization can look like after change; provide data, evidence, and success stories for inspiring change; identify best practices for how to manage change; create a baseline or yardstick by which to evaluate the impact of earlier changes.

Frontier techniques are those most suitable for efficiency and productivity analysis (Murillo-Zamorano 2004; Margono et al. 2011; Bogetoft, Otto 2011; Bojnec, Latruffe 2011; Atici, Ulucan 2011; Hajiagha et al. 2013). These methods can be grouped into parametric and nonparametric as well as into deterministic and stochastic ones. This study employs a deterministic non-parametric method, data envelopment analysis, which requires no $a$ priori specification of the functional form of the underlying production function. Furthermore, productivity indices are employed to analyse the changes in productivity. The two seminal methods are usually employed, namely Malmquist and Luenberger productivity indices (Ippoliti, Falavigna 2012; Tohidi et al. 2012).

On the other hand, the efficiency can be analysed at various levels, namely at the firm, sector, and nation level. The assessment of inter-sectorial patterns of efficiency provides a rationale for strategic management for both private and public decision makers. Indeed, the comparison of efficiency across different sector of Lithuanian economy has been by the means of financial ratios (Baležentis et al. 2012). Therefore, there is a need for further studies on the area. Our study aims at analysing the productive efficiency across different sectors of Lithuanian economy by the means of the Malmquist productivity index. It is worth to be noted, that the latter method has not been applied for analysis of the Lithuanian economy.

The economic research often involves multiple conflicting objectives and criteria (Zavadskas, Turskis 2011). In our case, we have different efficiency and productivity change indicators. Accordingly the multi-criteria decision making method MULTIMOORA (Brauers, Zavadskas 2006, 2010, 2011) is employed to summarize these indicators and provide an integrated ranking of the economic sectors.

The rest of the paper is structured as follows. Section 1 presents the measures of efficiency as well as Malmquist productivity index. The following Section 2 gives the preliminaries for data envelopment analysis. The multi-criteria decision making method MULTIMOORA is described in Section 3. Finally, the last section discusses the results of the research. 


\section{Productive technology and Malmquist index}

This section presents the main concepts of efficiency and productivity. The first sub-section describes the very definition of efficiency, whereas the second one presents the Malmquist productivity index. The Malmquist productivity index enables to quantify the changes in firm-specific efficiency as well as global shift in the production frontier.

\subsection{Measures of efficiency}

In order to relate the Debreu-Farrell measures to the Koopmans definition of efficiency, and to relate both to the structure of production technology, it is useful to introduce some notation and terminology (Fried et al. 2008). Let producers use inputs $x=\left(x_{1}, x_{2}, \ldots, x_{m}\right) \in \mathfrak{R}_{+}^{m}$ to produce outputs $y=\left(y_{1}, y_{2}, \ldots, y_{n}\right) \in \mathfrak{R}_{+}^{n}$. Production technology then can be defined in terms of the production set:

$$
T=\{(x, y) \mid x \text { can produce } y\} .
$$

Thus, Koopmans efficiency holds for an input-output bundle $(x, y) \in T$ if, and only if, $\left(x^{\prime}, y^{\prime}\right) \notin T$ for $\left(-x^{\prime}, y^{\prime}\right) \geq(-x, y)$.

Technology set can also be represented by output correspondence set:

$$
O(x)=\{y \mid(x, y) \in T\} .
$$

The isoquants or efficient boundaries of the sections of $T$ can be defined in radial terms as follows (Farrell 1957). Every $y \in \mathfrak{R}_{+}^{n}$ has an input isoquant:

$$
\text { isoI }(y)=\{x \mid x \in I(y), \lambda x \notin I(y), \lambda<1\} .
$$

Similarly, every $x \in \mathfrak{R}_{+}^{m}$ has an output isoquant:

$$
\text { isoO }(x)=\{y \mid y \in O(x), \lambda x \notin O(x), \lambda>1\} .
$$

In addition, DMUs might be operating on the efficiency frontier defined by Eqs. (3)-(4), albeit still use more inputs to produce the same output if compared to another efficient DMU. In this case the former DMU experiences a slack in inputs. The following subsets of the boundaries $I(y)$ and $O(x)$ describe Pareto-Koopmans efficient firms:

$$
\text { effO }(x)=\left\{y \mid y \in O(x), y^{\prime} \notin O(x), \forall y^{\prime} \geq y, y^{\prime} \neq y\right\} .
$$

Note that $e f f O(x) \subseteq i s o O(x) \subseteq O(x)$.

There are two types of efficiency measures, namely Shepard distance function, and Farrell distance function. These functions yield the distance between an observation and the efficiency frontier. Shepard (1953) defined the following output distance function:

$$
D_{O}(x, y)=\min \{\theta \mid(x, y / \theta) \in O(x)\} \text {. }
$$

Similarly, the following equations hold for the Farrell output-oriented measure:

$$
\operatorname{TE}_{O}(x, y)=\max \{\varphi \mid(x, \varphi y) \in O(x)\} ;
$$




$$
T E_{O}(x, y)=1 / D_{O}(x, y),
$$

where: $T E_{O}(x, y) \geq 1$ for $y \in O(x)$, and $T E_{O}(x, y)=1$ for $y \in i \operatorname{soO}(x)$.

\subsection{The Malmquist productivity index}

Measurement of the total factor productivity (TFP) of a certain DMU involves measures for both technological and firm-specific developments. As Bogetoft and Otto (2011) put it, firm behaviour changes over time should be explained in terms of special initiatives as well as technological progress. The benchmarking literature (Coelli et al. 2005; Bogetoft, Otto 2011; Ramanathan 2003) suggests Malmquist productivity index being the most celebrated TFP measure. Hence, this section describes the preliminaries of Malmquist index.

Färe et al. (2008) firstly describe productivity as the ratio of output $y$ over input $x$. Thereafter, the productivity can be measured by employing the output distance function of Shepard (1953):

$$
D_{o}^{t}(x, y)=\min \left\{\theta:(x, y / \theta) \in T^{t}\right\},
$$

where $T^{t}$ stands for the technology set (production possibility set) of the period $t$. This function is equal to unity if and only if certain input and output set belongs to production possibility frontier.

The Malmquist productivity index (Malmquist 1953) can be employed to estimate TFP changes of single firm over two periods (or vice versa), across two production modes, strategies, locations etc. In this study we shall focus on output-oriented Malmquist productivity index and apply it to measure period-wise changes in TFP. The output-oriented Malmquist productivity index due to Caves et al. (1982) is defined as:

$$
M_{o}=\left(M_{o}^{0} \cdot M_{o}^{1}\right)^{1 / 2}=\left(\frac{D_{o}^{0}\left(x^{1}, y^{1}\right)}{D_{o}^{0}\left(x^{0}, y^{0}\right)} \frac{D_{o}^{1}\left(x^{1}, y^{1}\right)}{D_{o}^{1}\left(x^{0}, y^{0}\right)}\right)^{1 / 2},
$$

with indexes 0 and 1 representing respective periods. The two terms in brackets follows the structure of Fisher's index. Consequently a number of studies (Färe et al. 1992, 1994; Ray, Desli 1997; Simar, Wilson 1998; Wheelock, Wilson 1999) attempted to decompose the latter index into different terms each explaining certain factors of productivity shifts. Specifically, Färe et al. (1992) decomposed productivity change into efficiency change (EC or catching up) and technical change (TC or shifts in the frontier):

$$
M_{o}=E C \cdot T C,
$$

where:

$$
E C=D_{o}^{1}\left(x^{1}, y^{1}\right) / D_{o}^{0}\left(x^{0}, y^{0}\right)
$$

and

$$
T C=\left(\frac{D_{o}^{0}\left(x^{1}, y^{1}\right)}{D_{o}^{1}\left(x^{1}, y^{1}\right)} \frac{D_{o}^{0}\left(x^{0}, y^{0}\right)}{D_{o}^{1}\left(x^{0}, y^{0}\right)}\right)^{1 / 2}
$$


EC measures the relative technical efficiency change. The index becomes greater than unity in case the firm approaches frontier of the current technology. TC indicates whether the technology has progressed and thus moved further away from the observed point. In case of technological progress, the TC becomes greater than unity; and that virtually means that more can be produced using fewer resources. Given the Malmquist productivity index measures TFP growth, improvement in productivity will be indicated by values greater than unity, whereas regress - by that below unity.

An important issue associated with the decomposition a la Färe et al. (1992) is that of returns to scale. In this case Eqs. (9)-(13) represent distance functions relying on the assumption of the constant returns to scale (CRS) rather than variable returns to scale (VRS). As a result the efficiency change component, $E C$, catches both the pure technical efficiency change and scale change. The latter two terms were defined by Färe et al. (1994) who offered the decomposition of the Malmquist productivity index under assumption of VRS. Indeed, macro-level studies do often assume the underlying production technology as a CRS technology.

The following Fig. 1 presents a graphical interpretation of the input Malmquist productivity index. Here, the point $A$ denotes an initial production plan in period $t$, whereas point $B$ stands for another production plan during period $t+1$. Meanwhile, the two isoquants, isoOt and isoOt+1, represent the efficient technology during periods $t$ and $t+1$, respectively. The two points $\mathrm{A}$ and $\mathrm{B}$ are projected onto efficiency frontiers at the points $A t$ and $B t$ or $A t+1$ and $B t+1$ depending on the reference period. After achieving the full efficiency, a decision making unit (DMU) would move from point A towards point At. The change in inputs, however, makes the DMU to move along the efficiency frontier towards point $B t$. It is the technological innovation that makes the frontier shift and thus the point $B t+1$ is achieved. Meanwhile, the DMU experiences certain technical inefficiency and remains operating in point $B t+1$. The Malmquist productivity index quantifies both the frontier shift and inefficiency change.

Specifically, the two components of the Malmquist productivity index, EC and TC, can be explained in terms of Fig. 1. The Malmquist productivity index can be obtained as follows (Färe et al. 2008):

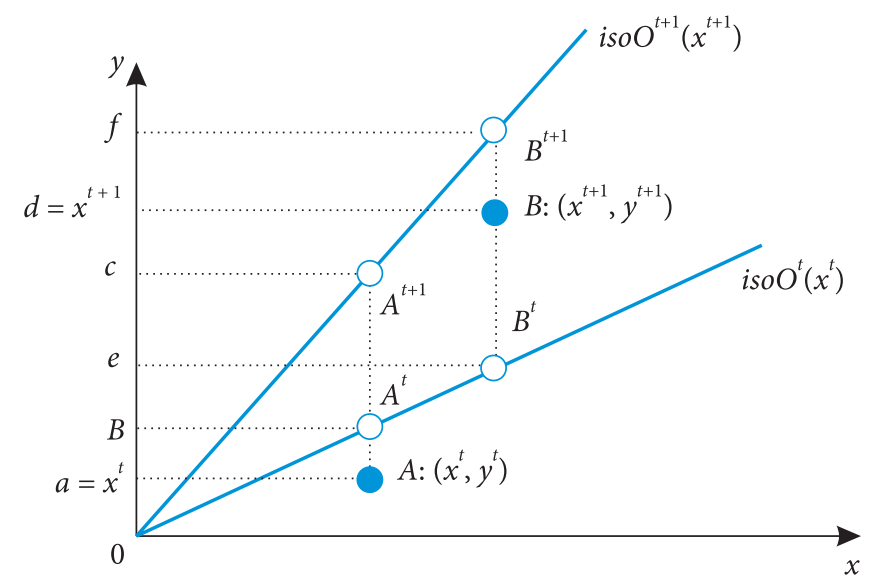

Fig. 1. The output Malmquist productivity index 


$$
M_{o}=\left(\frac{0 d / 0 e}{0 a / 0 b} \frac{0 d / 0 f}{0 a / 0 c}\right)^{1 / 2} .
$$

Similarly, its components for efficiency change and technical change are given by:

$$
\begin{gathered}
E C=\frac{0 d / 0 f}{0 a / 0 b} \\
T C=\left(\frac{0 d / 0 e}{0 d / 0 f} \frac{0 a / 0 b}{0 a / 0 c}\right)^{1 / 2} .
\end{gathered}
$$

\section{Preliminaries for Data Envelopment Analysis}

The distance functions used in the computations of the Malmquist productivity index (cf. Section 2) can be obtained by the virtue of the frontier methods. In this study we are to employ the non-parametric deterministic method, viz. Data Envelopment Analysis (DEA).

DEA is a nonparametric method of measuring the efficiency of a decision-making unit (DMU) such as a firm or a public-sector agency (Ray 2004). The very term of efficiency was initially defined by Debreu (1951) and then by Koopmans (1951). Debreu discussed the question of resource utilization at the aggregate level, whereas Koopmans offered the following definition of an efficient DMU: A DMU is fully efficient if and only if it is not possible to improve any input or output without worsening some other input or output. Due to similarity to the definition of Pareto efficiency, the former is called Pareto-Koopmans Efficiency. Finally, Farrell (1957) summarized works of Debreu and Koopmans thus offering frontier analysis of efficiency and describing two types of economic efficiency, namely technical efficiency and allocative efficiency (indeed, a different terminology was used at that time). The concept of technical efficiency is defined as the capacity and willingness to produce the maximum possible output from a given bundle of inputs and technology, whereas the allocative efficiency reflects the ability of a DMU to use the inputs in optimal proportions, considering respective marginal costs (Kalirajan, Shand 2002). However, Farrell (1957) did not succeed in handling Pareto-Koopmans Efficiency with proper mathematical framework.

The modern version of DEA originated in studies of A. Charnes, W. W. Cooper and E. Rhodes (Charnes et al. 1978, 1981). Hence, these DEA models are called CCR models. Initially, the fractional form of DEA was offered. However, this model was transformed into input- and output-oriented multiplier models, which could be solved by means of the linear programming (LP). In addition, the dual CCR model (i.e. envelopment program) can be described for each of the primal programs (Cooper et al. 2007; Ramanathan 2003).

Unlike many traditional analysis tools, DEA does not require to gather information about prices of materials or produced goods, thus making it suitable for evaluating both private- and public-sector efficiency. Suppose that there are $j=1,2, \ldots, t, \ldots, N$ DMUs, each producing $r=$ $1,2, \ldots, m$ outputs from $i=1,2, \ldots, n$ inputs. Hence, DMU $t$ exhibits input-oriented technical efficiency $\theta_{t}$, whereas output-oriented technical efficiency is a reciprocal number $\theta_{t}=1 / \phi_{t}$. The output-oriented technical efficiency $\phi_{t}$ may be obtained by solving the following multiplier DEA program: 


$$
\begin{aligned}
& \left(D_{O}(x, y)\right)^{-1}=\phi_{t}=\max _{\phi, \lambda_{k}} \phi, \\
& \sum_{j=1}^{N} \lambda_{j} x_{i}^{j} \leq x_{i}^{t}, \quad i=1,2, \ldots, n ; \\
& \sum_{j=1}^{N} \lambda_{j} y_{r}^{j} \geq \phi y_{r}^{t}, \quad r=1,2, \ldots, m ; \\
& \lambda_{j} \geq 0, \quad j=1,2, \ldots, N ;
\end{aligned}
$$

$\phi_{t}$ unrestricted.

In Eq. (17), coefficients $\lambda_{j}$ are weights of peer DMUs. Noteworthy, this model presumes existing CRS, which is rather arbitrary condition. CRS indicates that the manufacturer is able to scale the inputs and outputs linearly without increasing or decreasing efficiency (Ramanathan 2003). Whereas the CRS constraint was considered over-restrictive, the BCC (Banker, Charnes, and Cooper) model was introduced (Banker et al. 1984). The CRS presumption was overridden by introducing a convexity constraint $\sum_{j=1}^{N} \lambda_{j}=1$, which enabled to tackle the VRS. The BBC model, hence, can be written by supplementing Eq. (17) with a convexity constraint $\sum_{j=1}^{N} \lambda_{j}=1$.

The best achievable input can therefore be calculated by multiplying actual input by technical efficiency of certain DMU. On the other hand, the best achievable output is obtained by dividing the actual output by the same technical efficiency $\theta_{t}=1 / \phi_{t}$, where $\phi_{t}$ is obtained from Eq. (17). The difference between actual output and the potential one is called slack. In addition it is possible to ascertain whether a DMU operates under increasing returns to scale (IRS), CRS, or decreasing returns to scale (DRS). CCR measures gross technical efficiency (TE) and hence resembles both TE and scale efficiency (SE); whereas BCC represents pure TE. As a result, pure SE can be obtained by dividing CCR TE by BCC TE. Noteworthy, technical efficiency describes the efficiency in converting inputs to outputs, while scale efficiency recognizes that economy of scale cannot be attained at all scales of production (Ramanathan 2003).

\section{The MULTIMOORA method}

In order to summarize the different efficiency and productivity indicators obtained by the means of DEA and Malmquist productivity index, one can employ a multi-criteria decision making method. The MULTIMOORA method will be applied to perform an integrated assessment of efficiency across the Lithuanian economic sectors. This section, hence, briefly presents the MULTIMOORA method and the Dominance theory.

Chakraborty (2011) compared the six celebrated MCDM methods, viz. MOORA, AHP, TOPSIS, VIKOR, ELECTRE, and PROMETHEE in terms of computational time, simplicity, mathematical calculations, stability, and information type. The ELECTRE and PROMETHEE 
methods can be described as those of partial aggregation (Schärlig 1985). These methods require moderate calculations which include some subjectivity in choosing preference functions etc. The TOPSIS method relies solely on the reference point approach; however, it defines both the positive and the negative ideal solutions for comparison of the alternatives. The Analytical Hierarchy process (AHP) is time consuming. The VIKOR method utilizes both value measurement (complete aggregation) techniques and reference point approach. However, it mixes the results provided by these techniques and thus might provide some inconsistent ranking. The comparison of Chakraborty (2011) attributed MOORA with the best ratings against all of criteria save information type, given MOORA cannot handle mixedtype information. The fuzzy MULTIMOORA as well as other MCDM methods, however, does enable one to perform the data fusion by involving linguistic variables. An interested reader could consult the paper by Brauers and Zavadskas (2012) which defines the set of robustness conditions which are met by the MULTIMOORA method. Accordingly we will employ the MULTIMOORA method for comparison of the economic sector performance.

The MULTIMOORA method begins with a response matrix $X$ where its elements $x_{i j}$ denote $i$ th alternative of $j$ th objective $(i=1,2, \ldots, m$ and $j=1,2, \ldots, n)$. The method consists of three parts, viz. the Ratio System, the Reference Point approach, and the Full Multiplicative Form.

The Ratio System of MOORA. Ratio system employs the vector data normalization by comparing alternative of an objective to all values of the objective:

$$
x_{i j}^{*}=w_{j} \frac{x_{i j}}{\sqrt{\sum_{i=1}^{m} x_{i j}^{2}}},
$$

where $x_{i j}^{*}$ denotes $i$ th alternative of $j$ th objective and $w_{j}$ is weight of the $j$ th criterion, $\sum_{j} w_{j}=1$. In the absence of negative values, these numbers belong to the interval $[0 ; 1]$. These indicators are added (if desirable value of indicator is maximum) or subtracted (if desirable value is minimum). Thus, the summarizing index of each alternative is derived in this way:

$$
y_{i}^{*}=\sum_{j=1}^{g} x_{i j}^{*}-\sum_{j=g+1}^{n} x_{i j}^{*},
$$

where $g=1,2, \ldots, n$ denotes number of objectives to be maximized. Then every ratio is given the rank: the higher the index, the higher the rank.

The Reference Point of MOORA. Reference point approach is based on the Ratio System. The Maximal Objective Reference Point (vector) is found according to ratios found in Eq. (18). The $j$ th coordinate of the reference point can be described as $r_{j}=\max _{i} x_{i j}^{*}$ in case of maximization. Every coordinate of this vector represents maximum or minimum of certain objective (indicator). Then every element of the normalized response matrix is recalculated and final rank is given according to deviation from the reference point and the Min-Max Metric of Tchebycheff:

$$
\min _{i}\left(\max _{j}\left|r_{j}-x_{i j}^{*}\right|\right) .
$$


The Full Multiplicative Form and MULTIMOORA. Brauers and Zavadskas (2010) proposed MOORA to be updated by the Full Multiplicative Form method embodying maximization as well as minimization of purely multiplicative utility function. Overall utility of the $i$ th alternative can be expressed as dimensionless number:

$$
U_{i}^{\prime}=\frac{A_{i}}{B_{i}}
$$

where $A_{i}=\prod_{j=1}^{g}\left(x_{i j}\right)^{w_{j}}$ denotes the product of objectives of the $i$ th alternative to be maximized with $g=1, \ldots, n$ being the number of objectives to be maximized and where $B_{i}=\prod_{j=g+1}^{n}\left(x_{i j}\right)^{w_{j}}$

denotes the product of objectives of the $i$ th alternative to be minimized with $n-g$ being the number of objectives (indicators) to be minimized. Thus MULTIMOORA summarizes MOORA (i.e. Ratio System and Reference point) and the Full Multiplicative Form. Brauers and Zavadskas (2011) proposed the dominance theory to summarize the three ranks provided by different parts of MULTIMOORA.

Absolute Dominance means that an alternative, solution or project is dominating in ranking all other alternatives, solutions or projects which are all being dominated. This absolute dominance shows as rankings for MULTIMOORA: (1-1-1). General Dominance in two of the three methods is of the form with $\mathrm{a}<\mathrm{b}<\mathrm{c}<\mathrm{d}$ :

$$
\begin{aligned}
& (\mathrm{d}-\mathrm{a}-\mathrm{a}) \text { is generally dominating }(\mathrm{c}-\mathrm{b}-\mathrm{b}) \text {; } \\
& (\mathrm{a}-\mathrm{d}-\mathrm{a}) \text { is generally dominating }(\mathrm{b}-\mathrm{c}-\mathrm{b}) \text {; } \\
& (\mathrm{a}-\mathrm{a}-\mathrm{d}) \text { is generally dominating }(\mathrm{b}-\mathrm{b}-\mathrm{c}) \text {; }
\end{aligned}
$$

and further transitiveness plays fully.

Transitiveness. If $a$ dominates $b$ and $b$ dominates $c$ than also $a$ will dominate $c$. Overall Dominance of one alternative on the next one. For instance (a-a-a) is overall dominating ( $b-b-b)$ which is overall being dominated, with ( $b-b-b)$ following immediately ( $a-a-a)$ in rank (transitiveness is not playing). Absolute Equability has the form: for instance (e-e-e) for 2 alternatives. Partial Equability of 2 on 3 exists e. g. (5-e-7) and (6-E-3). Despite all distinctions in classification some contradictions remain possible in a kind of Circular Reasoning. We can cite the case of:

$$
\begin{aligned}
\text { Object A }(11-20-14) & \succ \text { Object B }(14-16-15) ; \\
\text { Object B }(14-16-15) & \succ \text { Object C }(15-19-12) \text {; but } \\
\text { Object C }(15-19-12) & \succ \text { Object A }(11-20-14) .
\end{aligned}
$$

Here, the operator $\succ$ represents a General Dominance. In such a case the same ranking is given to the three objects. 


\section{Results of the research}

The research relies on National Accounting data provided by Statistics Lithuania (2012). We have used the aggregates for 35 economic activities (NACE 2 classification), see Table A1 in Appendix A for details. The data cover the period of 2000-2010.

The gross value added generated in certain sector was chosen as the output variable, whereas intermediate consumption, remuneration, and fixed capital consumption were treated as inputs. The latter three indicators enable to tackle the total factor productivity and thus are usually employed for productivity analysis (Piesse, Thirtle 2000). The FEAR package (Wilson 2010) was employed for the analysis.

Firstly, the VRS technical efficiency scores were estimated by employing the output oriented DEA model as described in Section 2. The following Fig. 2 presents these estimates for years 2000 and 2010. The weighted average was obtained by weighting the efficiency scores by the value added generated in the respective sector during the base year. As the results suggest, the mean efficiency increased from 0.79 in 2000 up to 0.85 in 2010 . These efficiency scores imply that there was a $21 \%$ gap in output for 2000 which decreased to $15 \%$ in 2010 given technological frontier of those periods. Note that the contemporaneous technological frontier is defined by the efficient DMUs viz. economic sectors, and these gaps are therefore incomparable in absolute terms. The application of Malmquist index will enable to identify the shifts of the efficiency frontier. As one can note, the four sectors remained operating on the efficiency frontier during 2000-2010: pharmaceutical products (C21), wholesale and retail trade $(\mathrm{G})$, real estate activities $(\mathrm{L})$, and education $(\mathrm{P})$.

As in 2000, the whole manufacturing sector (activities C22 to C33) and utility services (D and E) exhibited the lowest values of technical efficiency ranging between 0.32 and 0.49 . Most of these sectors, however, experienced the steepest increase in efficiency amounting to some $50 \%$ of the initial efficiency scores and thus graduated the group of the worst performing sectors. Meanwhile the most significant decrease in efficiency was observed for the primary sector (A and B). This indicates the need for modernization in these sectors. Anyway, it may also be related to the overall transformation of the economy. Scientific research and development (M72) was specific with particularly high decrease in efficiency probably caused by rising compensations for employees.

The Malmquist index given by Eqs. (9)-(13) was employed to examine the productivity changes across different economic sectors. Initially, we estimated the shift in productivity between years 2000 and 2010 (Fig. 3). As one can note, the most significant increase in productivity was observed for pharmaceutical (C21) and chemical (C20) production. Indeed, these industries were positively affected by the investments and market enlargement following the accession to the European Union. Similar trends were also exhibited in sectors of electronics (C26), machinery (C28), and transport equipment (C29, C30). Although the scientific research sector (M72) was specific with the decreased efficiency score, it enjoyed an increase in productivity. At the other end of spectrum, the two primary sectors (A and B) demonstrated a tremendous decrease in productivity. Specifically, the agricultural sector was specific with decrease of $40 \%$, whereas mining and quarrying with that of some 23\%. Publishing industry (J58-J60) was also experiencing the decreasing productivity: the 


\section{$2010 \square 2000$}

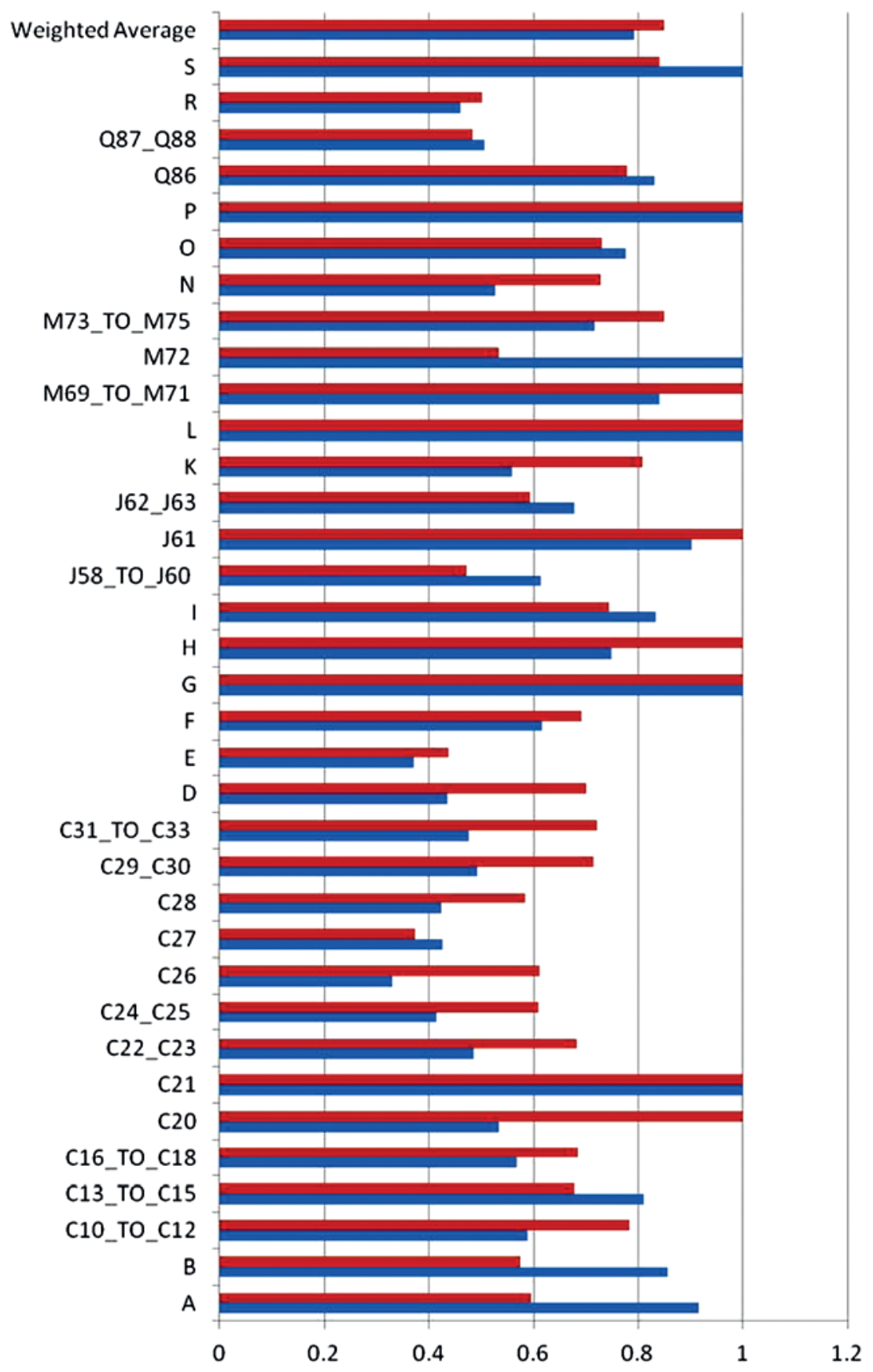

Fig. 2. Technical efficiency scores across economic sectors, 2000 and 2010

Note: see Table A1 in Appendix A for abbreviations. 
Malmquist index for that sector suggested that productivity there dropped by some $28 \%$ thanks to decreasing sectoral efficiency. Indeed, cancellation of value-added tax exemptions might have caused the efficiency decrease in the latter sector.

The decomposition of the Malmquist index enables to identify the underlying reasons in productivity change. As Fig. 3 suggests, the increase in productivity of the pharmaceutical sector was driven by both inner innovation (efficiency change) and shift in the production frontier (technology change). As for chemical sector, these two factors have a positive effect, however catch-up effect was stronger. In general, the technology effect was positive for all sectors with exception of public administration $(\mathrm{O})$ and education $(\mathrm{P})$ which were subject to a negative shift in the efficiency frontier (i.e. the reference sector exhibited higher efficiency in 2010).

In addition, the Malmquist productivity indices were computed for each period of the two subsequent years between 2000 and 2010. The results indicate that the total factor productivity had been decreasing during 2003-2006 and has been recovering since 2008 (Fig. 4). The analysis of the cumulative change in the total factor productivity implies that the productivity has never been decreased below the level of 2000 and had reached its peak in 2007 when the accumulated growth since 2000 reached some $6 \%$. As for the whole period of 2000-2010, the accumulated growth rate was some $4 \%$. Furthermore, the cumulative change in total factor productivity has never been below the value unity what indicates that the Lithuanian economy was rather persistent throughout the economic downturns.

In order to better understand the driving forces of change in total factor productivity, the mean values of the Malmquist components are depicted in Fig. 5. As one can note, the overall productivity (i.e. shifts in the production frontier) were generally downwards until 2005 and has been following an opposite trend afterwards. Meanwhile, the catch-up effect exhibited an inverse movement: firm-specific increase in productivity had been increasing until 2005 and decreasing ever since. The results imply that the recent economic downturn negatively affected the firm-specific innovations, whereas the overall productivity of the economy has increased possibly due to appropriate managerial decisions. The reported results also imply that efficiency and changes in productivity varied across the economic sectors throughout 2000-2010.

The steep increases in productivity, however, do not necessarily mean that a certain sector is operating efficiently in relative terms. One thus needs to take into account the level of efficiency as well as productivity changes when performing a robust comparison. Furthermore, these indicators and indices are time-variant and thus might fluctuate in a wider or tighter range. Indeed, higher variation of these indicators is associated with higher risk and uncertainty in respective economic sectors. To cap it all, there is a dichotomy between efficiency and productivity as well as between mean values and variation of the analysed criteria. The multi-criteria decision making method MULTIMOORA will therefore be employed to simultaneously consider these criteria identifying different objectives:

1. the mean technical efficiency score for 2000-2010 (to be maximized);

2. coefficient of variation of the technical efficiency scores (to be minimized);

3. the mean change in total factor productivity for 2000-2010 (to be maximized);

4. coefficient of variation of change in total factor productivity (to be minimized). 


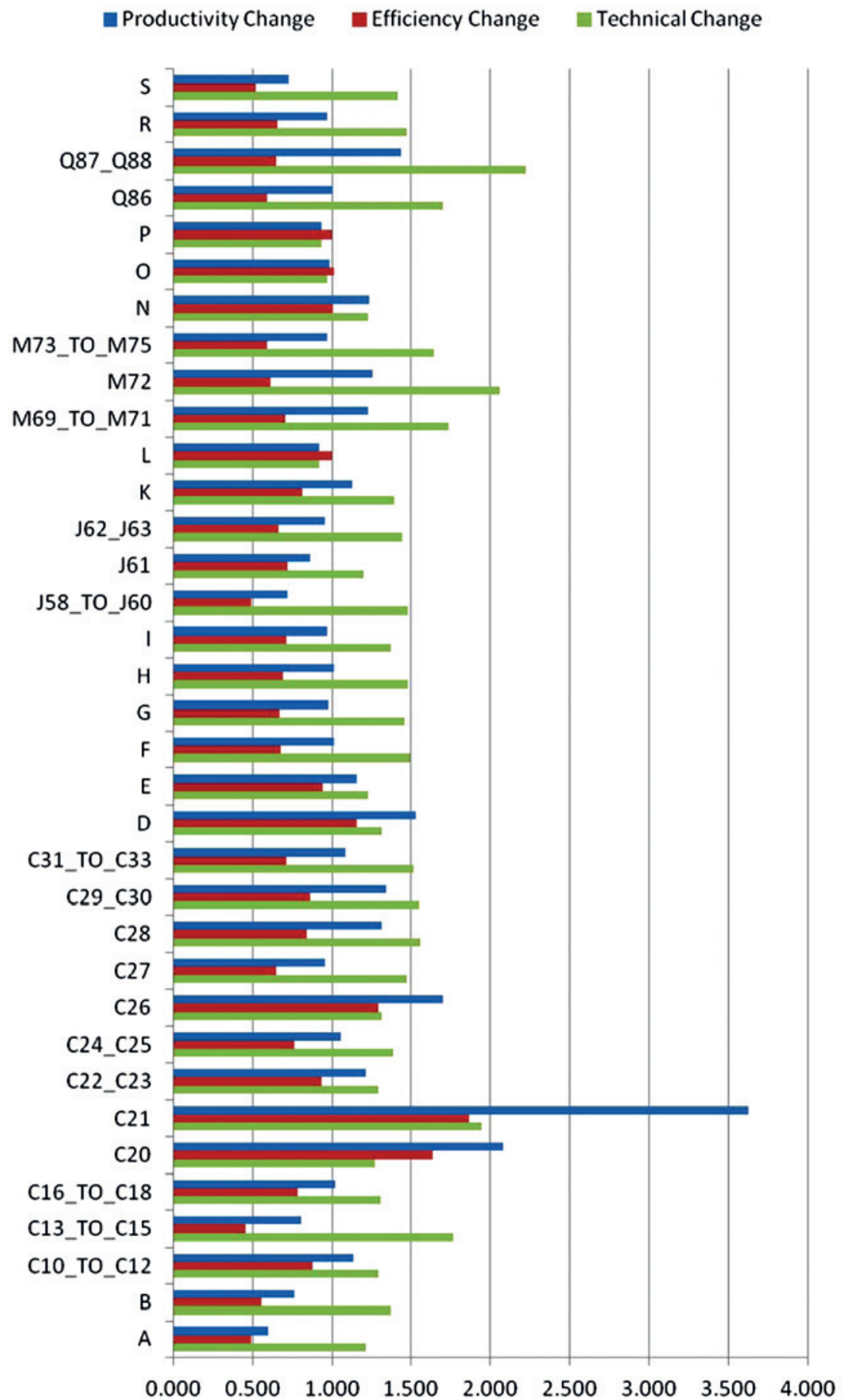

Fig. 3. Malmquist productivity index across economic sectors, 2010 compared to 2000 Note: see Table A1 in Appendix A for abbreviations. 


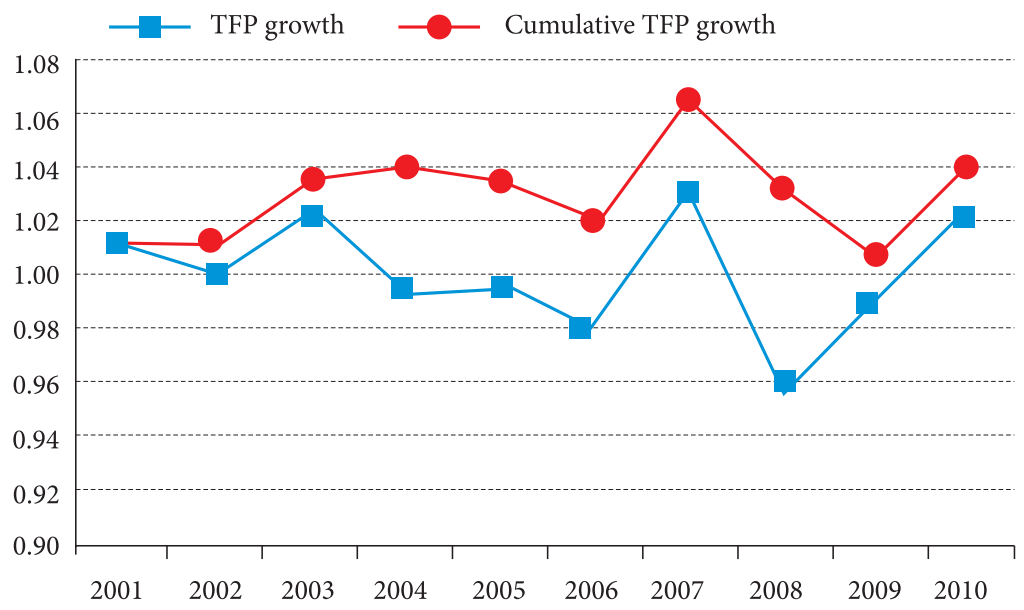

Fig. 4. Changes in the mean total factor productivity (TFP) during 2000-2010

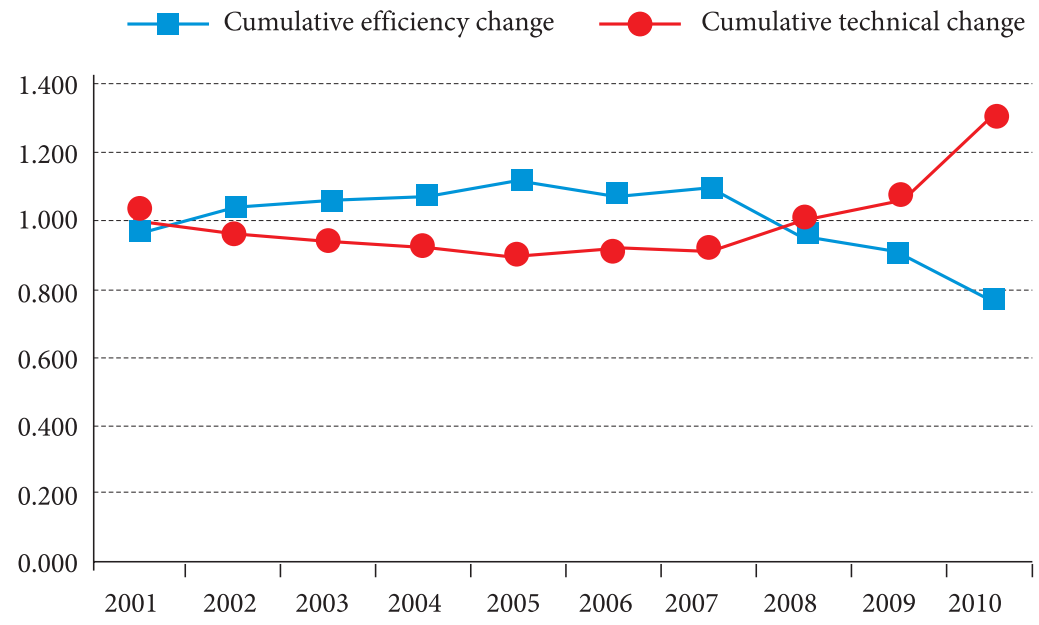

Fig. 5. Decomposition of the Malmquist productivity index for 2000-2010

The presented set of indicators has the following implications. First, a sector specific with high values of technical efficiency might be experiencing decreasing total factor productivity and thus require certain managerial and institutional measures to be taken. Second, a sector exhibiting increasing total factor productivity might still remain an inefficient one. Third, a high variance in these indicators indicates high volatility of performance and should also attract certain attention. The initial data are given in Table A2, Appendix A.

The initial decision matrix (Table A2, Appendix A) was normalized by the virtue of Eq. (18). Subsequently, the economic sectors were ranked according to the Ratio System approach, cf. Eq. (19). The normalized values were also employed to rank the economic 
sectors upon the Reference Point approach, cf. Eq. (20). Finally, zero values in the initial decision matrix were changed into 0.001 and thus Eq. (21) was applied to order the economic sectors according to the Multiplicative Form approach. Thus, each of economic sectors was attributed with the three ranks. The dominance theory, therefore, was employed to aggregate these ratings. Table 1 presents all of the discussed ranks.

Table 1. Ranks of the economic sectors provided by the different parts of the MULTIMOORA method

\begin{tabular}{|c|c|c|c|c|}
\hline Economic sector & Ratio System & Reference Point & $\begin{array}{l}\text { Multiplicative } \\
\text { Form }\end{array}$ & $\begin{array}{c}\text { Final Rank } \\
\text { (MULTIMOORA) }\end{array}$ \\
\hline G & 1 & 1 & 1 & 1 \\
\hline $\mathrm{L}$ & 2 & 2 & 2 & 2 \\
\hline $\mathrm{P}$ & 3 & 5 & 3 & 3 \\
\hline I & 4 & 4 & 5 & 4 \\
\hline Q86 & 5 & 3 & 6 & 5 \\
\hline J61 & 6 & 7 & 7 & 6 \\
\hline M73_TO_M75 & 8 & 8 & 8 & 7 \\
\hline $\mathrm{H}$ & 7 & 12 & 9 & 8 \\
\hline $\mathrm{O}$ & 9 & 6 & 10 & 9 \\
\hline M69_TO_M71 & 10 & 11 & 11 & 10 \\
\hline $\mathrm{C} 21$ & 11 & 29 & 4 & 11 \\
\hline $\mathrm{E}$ & 12 & 9 & 12 & 12 \\
\hline C16_TO_C18 & 13 & 10 & 14 & 13 \\
\hline C10_TO_C12 & 14 & 15 & 16 & 14 \\
\hline C31_TO_C33 & 15 & 16 & 13 & 15 \\
\hline $\mathrm{F}$ & 16 & 21 & 15 & 16 \\
\hline J58_TO_J60 & 17 & 13 & 18 & 17 \\
\hline $\mathrm{N}$ & 18 & 14 & 17 & 18 \\
\hline B & 19 & 20 & 19 & 19 \\
\hline C13_TO_C15 & 20 & 25 & 20 & 20 \\
\hline C24_C25 & 21 & 19 & 21 & 21 \\
\hline $\mathrm{C} 28$ & 22 & 18 & 23 & 22 \\
\hline $\mathrm{D}$ & 23 & 24 & 22 & 23 \\
\hline $\mathrm{R}$ & 24 & 17 & 26 & 24 \\
\hline C29_C30 & 25 & 28 & 24 & 25 \\
\hline C22_C23 & 26 & 26 & 25 & 26 \\
\hline$S$ & 27 & 23 & 27 & 27 \\
\hline J62_J63 & 29 & 22 & 28 & 28 \\
\hline C27 & 28 & 30 & 29 & 29 \\
\hline
\end{tabular}


Continued Table 1

\begin{tabular}{ccccc}
\hline Economic sector & Ratio System & Reference Point & $\begin{array}{c}\text { Multiplicative } \\
\text { Form }\end{array}$ & $\begin{array}{c}\text { Final Rank } \\
\text { (MULTIMOORA) }\end{array}$ \\
\hline A & 30 & 27 & 30 & $\mathbf{3 0}$ \\
Q87_Q88 & 31 & 31 & 31 & 31 \\
C26 & 32 & 32 & 35 & $\mathbf{3 2}$ \\
C20 & 33 & 34 & 33 & $\mathbf{3 3}$ \\
K & 34 & 33 & 34 & $\mathbf{3 4}$ \\
M72 & 35 & 35 & 32 & $\mathbf{3 5}$ \\
\hline
\end{tabular}

The results indicate that the best performing sectors in terms of efficiency and productivity were those of wholesale and retail trade, real estate activities, education, hospitality, health, telecommunications, transport, legal services, accounting, advertising. Therefore, the services sector seems to be that most developed in Lithuania. Indeed, some of them, viz. education, hospitality, and health sectors, can prevail by providing services for foreign visitors and thus generating substantial revenues. Meanwhile, transport, legal services, accounting, and advertising sectors rely both on local and international customers. Finally, real estate, telecommunications, and trade sectors are mainly focused on domestic market and thus on the development of the remaining economic sectors in Lithuania.

The manufacturing sector followed the services. Pharmaceutical, wood, food, and furniture production exhibited the best performance amidst the manufacturing activities. Indeed, these sectors received substantial foreign investments and thus modernized their production technologies. Therefore, these sectors can be considered as those constituting the core of the Lithuanian economy. The construction sector was also attributed with rather high rank. The textile, metallurgy, machinery, transport equipment, and rubber industry operated less efficiently. Accordingly, certain fiscal and institutional measures should be considered to improve the situation in the latter sectors.

The multi-criteria analysis also suggested that the worst performing sectors were those of IT services, electrical equipment, agriculture, computer products, and electrical equipment. IT-related industries are likely to face the competition of the developing countries. Finally, financial and insurance activities as well as scientific research (R\&D) were placed at the very bottom. Indeed, the last two sectors were peculiar with rather high volatility of the efficiency indicators. As for the financial sector, these findings are almost imminent in the presence of the economic downturn. However, R\&D sector should be appropriately supported in order to create a basis for prospective activities. As European Commission (2011) reported, the Lithuanian knowledge-intensive business sectors, namely IT and $\mathrm{R} \& \mathrm{D}$, are specific with one of the largest backward dependence on the imported materials among the EU Member States. Therefore, this dependence should be reduced in order to maintain efficiency as well as competitiveness. 


\section{Conclusions}

The paper presented a multi-criteria framework for estimation of productive efficiency across economic sectors. The research was based on national accounting data. The data envelopment analysis was employed to estimate efficiency in terms of an output indicator (value added) and input indicators (intermediate consumption, capital consumption, and remunerations). The productivity change was quantified by employing the Malmquist index.

The results suggest that the mean efficiency increased from 0.79 in 2000 up to 0.85 in 2010. Specifically, the four sectors remained operating on the efficiency frontier during 2000-2010: pharmaceutical products, wholesale and retail trade, real estate activities, and education. The Malmquist productivity index was applied to estimate the productivity change. As for the whole period of 2000-2010, the accumulated growth rate of the total factor productivity was some $4 \%$. It is evident, that the economic crisis of 2007-2008 accelerated growth in the total factor productivity.

The multi-criteria analysis suggests that the best performing sectors were those of wholesale and retail trade, real estate activities, education, hospitality, health, telecommunications, transport, legal services, accounting, advertising. The manufacturing sector followed the services. Pharmaceutical, wood, food, and furniture production exhibited the best performance amidst the manufacturing activities. The multi-criteria analysis also suggested that the worst performing sectors were those of IT services, electrical equipment, agriculture, computer products, and electrical equipment. The fiscal and administrative easing should be designed for suchlike prospective sectors as $\mathrm{R} \& \mathrm{D}$ and IT which exhibited rather low performance. Furthermore, the excessive dependence of the latter sector should be reduced.

The carried out research, though, has some limitations. First, the selection of inputs and outputs is of crucial importance for DEA. Therefore, further studies should attempt to employ different sets of indicators for a more robust estimation of efficiency scores. Indeed, the currently available datasets prevented us from analysing physical quantities of energy etc. involved in the production process. Second, DEA is applicable to homogeneous decision making units. It is obvious that different economic activities are associated with rather different productive technologies. Therefore, the econometric analysis (e.g. stochastic frontier analysis) could be employed to tackle the heterogeneity existing among the economic sectors.

Further research should aim at employing different datasets and methods. Specifically, different types of the total factor productivity indices, namely Luenberger, Hicks-Moosteen, and extensions thereof, could be employed for the analysis. In addition sequential indices are likely to be more suitable for longitudinal productivity analysis.

\section{Acknowledgments}

This research was funded by the European Social Fund under the Global Grant measure (VP1-3.1-ŠMM-07-K-03-002). 


\section{References}

Atici, K. B.; Ulucan, A. 2011. A multiple criteria energy decision support system, Technological and Economic Development of Economy 17(2): 219-245. http://dx.doi.org/10.3846/20294913.2011.580563

Baležentis, A.; Baležentis, T.; Misiūnas, A. 2012. An integrated assessment of Lithuanian economic sectors based on financial ratios and fuzzy MCDM methods, Technological and Economic Development of Economy 18(1): 34-53. http://dx.doi.org/10.3846/20294913.2012.656151

Banker, R. D.; Charnes, A.; Cooper, W. W. 1984. Some models for estimating technical and scale inefficiencies in data envelopment analysis, Management Science 30(9): 1078-1092. http://dx.doi.org/10.1287/mnsc.30.9.1078

Bogetoft, P.; Otto, L. 2011. Benchmarking with DEA, SFA, and R. International Series in Operations Research and Management Science, Vol. 157. Springer. 352 p.

Bojnec, S.; Latruffe, L. 2011. Farm size and efficiency during transition: insights from Slovenian farms, Transformations in Business \& Economics 10(3): 104-116.

Brauers, W. K. M.; Zavadskas, E. K. 2006. The MOORA method and its application to privatization in a transition economy, Control and Cybernetics 35: 445-469.

Brauers, W. K. M.; Zavadskas, E. K. 2010. Project management by MULTIMOORA as an instrument for transition economies, Technological and Economic Development of Economy 16(1): 5-24. http://dx.doi.org/10.3846/tede.2010.01

Brauers, W. K. M.; Zavadskas, E. K. 2011. MULTIMOORA optimization used to decide on a bank loan to buy property, Technological and Economic Development of Economy 17(1): 174-188. http://dx.doi.org/10.3846/13928619.2011.560632

Brauers, W. K. M.; Zavadskas, E. K. 2012. Robustness of MULTIMOORA: a method for multi-objective optimization, Informatica 23(1): 1-25.

Caves, D. W.; Christensen, L. R.; Diewert, W. E. 1982. The economic theory of index numbers and the measurement of input, output, and productivity, Econometrica 50(6): 1393-1414. http://dx.doi.org/10.2307/1913388

Chakraborty, S. 2011. Applications of the MOORA method for decision making in manufacturing environment, International Journal of Advanced Manufacturing Technology 54(9-12): 1155-1166. http://dx.doi.org/10.1007/s00170-010-2972-0

Charnes, A.; Cooper, W. W.; Rhodes, E. 1978. Measuring the efficiency of decision making units, European Journal of Operational Research 2(6): 429-444. http://dx.doi.org/10.1016/0377-2217(78)90138-8

Charnes, A.; Cooper, W. W.; Rhodes, E. 1981. Evaluating program and managerial efficiency: an application of data envelopment analysis to program follow through, Management Science 27(6): 668-697. http://dx.doi.org/10.1287/mnsc.27.6.668

Coelli, T. J.; Rao, D. S. P.; O'Donnell, C. J.; Battese, G. E. 2005. An introduction to efficiency and productivity analysis. Springer. $349 \mathrm{p}$.

Cooper, W. W.; Seiford, L. M.; Tone, K. 2007. Data envelopment analysis: a comprehensive text with models, applications, references and DEA-Solver software. 2nd ed. Springer. $490 \mathrm{p}$.

Debreu, G. 1951. The coefficient of resource utilization, Econometrica 19(3): 273-292. http://dx.doi.org/10.2307/1906814

European Commission. 2011. European Competitiveness Report 2011. Commission staff working document SEC(2011) 1188. Luxembourg: Publications Office of the European Union. http://dx.doi.org/10.2769/30346

Färe, R.; Grosskopf, S.; Lindgren, B.; Roos, P. 1992. Productivity changes in Swedish pharmacies 1980-1989: a non-parametric Malmquist approach, Journal of Productivity Analysis 3(1-2): 85-101. http://dx.doi.org/10.1007/BF00158770 
Färe, R.; Grosskopf, S.; Margaritis, D. 2008. Efficiency and productivity: Malmquist and more, in Fried, H. O.; Lovell, C. A. K.; Schmidt, S. S. (Eds.). The Measurement of Productive Efficiency and Productivity. New York, Oxford University Press, 522-621. http://dx.doi.org/10.1093/acprof:oso/9780195183528.003.0005

Färe, R.; Grosskopf, S.; Norris, M.; Zhang, Z. 1994. Productivity growth, technical progress, and efficiency change in industrialized countries, American Economic Review 84: 66-83.

Farrell, M. J. 1957. The measurement of technical efficiency, Journal of the Royal Statistical Society, Series A 120(3): 253-281. http://dx.doi.org/10.2307/2343100

Fried, H. O.; Lovell, C. A. K.; Schmidt, S. S. 2008. Efficiency and productivity, in Fried, H. O.; Lovell, C. A. K.; Schmidt, S. S. (Eds.). The Measurement of Productive Efficiency and Productivity. New York, Oxford University Press, 3-91. http://dx.doi.org/10.1093/acprof:oso/9780195183528.003.0001

Hajiagha, S. H. R.; Akrami, H.; Zavadskas, E. K.; Hashemi, S. S. 2013. An intuitionistic fuzzy data envelopment analysis for efficiency evaluation under ucertainty: case of a finance and credit institution, E + M Ekonomie a Management (1): 128-137.

Ippoliti, R.; Falavigna, G. 2012. Efficiency of the medical care industry: evidence from the Italian regional system, European Journal of Operational Research 217(3): 643-652. http://dx.doi.org/10.1016/j.ejor.2011.10.010

Jack, L.; Boone, J. 2009. Sustainable change and benchmarking in the food supply chain, in Jack, L. (Ed.). Benchmarking in Food and Farming. Gower, 1-8.

Kalirajan, K. P.; Shand, R. T. 2002. Frontier production functions and technical efficiency measures, Journal of Economic Surveys 13(2): 149-172. http://dx.doi.org/10.1111/1467-6419.00080

Koopmans, T. C. 1951. An analysis of production as an efficient combination of activities, in Koopmans, T. C. (Ed.). Activity Analysis of Production and Allocation. Cowles Commission for Research in Economics, Monograph No. 13. New York: Wiley.

Latruffe, L. 2010. Competitiveness, productivity and efficiency in the agricultural and agri-food sectors. OECD Food, Agriculture and Fisheries Working Papers, No. 30, OECD Publishing. http://dx.doi.org/10.1787/5km91nkdt6d6-en

Malmquist, S. 1953. Index numbers and indifference surfaces, Trabajos de Estatistica 4(2): 209-242. http://dx.doi.org/10.1007/BF03006863

Margono, H.; Sharma, S. C.; Sylwester, K.; Al-Qalawi, U. 2011. Technical efficiency and productivity analysis in Indonesian provincial economies, Applied Economics 43(6): 663-672. http://dx.doi.org/10.1080/00036840802599834

Murillo-Zamorano, L. R. 2004. Economic efficiency and frontier techniques, Journal of Economic Surveys 18(1): 33-45. http://dx.doi.org/10.1111/j.1467-6419.2004.00215.x

Piesse, J.; Thirtle, C. 2000. A stochastic frontier approach to firm level efficiency, technological change, and productivity during the early transition in Hungary, Journal of Comparative Economics 28(3): 473-501. http://dx.doi.org/10.1006/jcec.2000.1672

Ray, S. C. 2004. Data envelopment analysis: theory and techniques for economics and operations research. Cambridge University Press. 353 p. http://dx.doi.org/10.1017/CBO9780511606731

Ray, S. C.; Desli, E. 1997. Productivity growth, technical progress, and efficiency change in industrialized countries: comment, American Economic Review 87: 1033-1039.

Ramanathan, R. 2003. An introduction to data envelopment analysis: a tool for performance measurement. Sage Publications. 201 p.

Schärlig, A. 1985. Décider sur plusieurs critères. Lausanne: Presses Polytechniques Romandes. 304 p.

Shepard, R. W. 1953. Cost and production functions. Princeton, New Jersey: Princeton University Press. $104 \mathrm{p}$. 
Simar, L.; Wilson, P. W. 1998. Productivity growth in industrialized countries. Discussion Paper \#9810, Institut de Statistique, Université Catholique de Louvain, Louvain-la-Neuve, Belgium.

Statistics Lithuania. 2012. Indicator database [online], [cited 1 September 2012]. Available from Internet: http://db1.stat.gov.lt/

Tohidi, G.; Razavyan, S.; Tohidnia, S. 2012. A global cost Malmquist Productivity index using data envelopment analysis, Journal of the Operational Research Society 63: 72-78. http://dx.doi.org/10.1057/jors.2011.23

Wheelock, D. C.; Wilson, P. W. 1999. Technical progress, inefficiency, and productivity change in U.S. banking, 1984-1993, Journal of Money, Credit, and Banking 31(2): 212-234. http://dx.doi.org/10.2307/2601230

Wilson, P. W. 2010. FEAR 1.15 User's Guide. Clemson University, Clemson, South Carolina.

Zavadskas, E. K.; Turskis, Z. 2011. Multiple criteria decision making (MCDM) methods in economics: an overview, Technological and Economic Development of Economy 17(2): 397-427. http://dx.doi.org/10.3846/20294913.2011.593291 


\section{APPENDIX A. ABBREVIATIONS AND INITIAL DATA FOR MULTI-CRITERIA ASSESSMENT}

Table A1. Aggregates of statistical classification of economic activities (NACE Rev. 2) used in the research

\begin{tabular}{|c|c|}
\hline NACE code & Economic activity \\
\hline A & Agriculture, forestry and fishing \\
\hline B & Mining and quarrying \\
\hline C10_TO_C12 & Manufacture of food products, beverages and tobacco \\
\hline C13_TO_C15 & Manufacture of textiles, wearing apparel, leather and related products \\
\hline C16_TO_C18 & Manufacture of wood, paper, printing and reproduction \\
\hline $\mathrm{C} 20$ & Manufacture of chemicals and chemical products \\
\hline $\mathrm{C} 21$ & Manufacture of basic pharmaceutical products and pharmaceutical preparations \\
\hline C22_C23 & Manufacture of rubber and plastics products \\
\hline C24_C25 & Manufacture of basic metals and fabricated metal products, except machinery \\
\hline $\mathrm{C} 26$ & Manufacture of computer, electronic and optical products \\
\hline $\mathrm{C} 27$ & Manufacture of electrical equipment \\
\hline $\mathrm{C} 28$ & Manufacture of machinery and equipment n.e.c. \\
\hline C29_C30 & Manufacture of transport equipment \\
\hline C31_TO_C33 & Manufacture of furniture; jewellery, musical instruments, toys \\
\hline $\mathrm{D}$ & Electricity, gas, steam and air conditioning supply \\
\hline $\mathrm{E}$ & Water supply; sewerage, waste management and remediation activities \\
\hline $\mathrm{F}$ & Construction \\
\hline G & Wholesale and retail trade; repair of motor vehicles and motorcycle \\
\hline $\mathrm{H}$ & Transportation and storage \\
\hline I & Accommodation and food service activities \\
\hline J58_TO_J60 & Publishing, motion picture, broadcasting activities \\
\hline J61 & Telecommunications \\
\hline J62_J63 & IT services \\
\hline K & Financial and insurance activities \\
\hline $\mathrm{L}$ & Real estate activities \\
\hline M69_TO_M71 & Legal and accounting activities; activities of head offices \\
\hline M72 & Scientific research and development \\
\hline M73_TO_M75 & Advertising and market research; other professional activity \\
\hline $\mathrm{N}$ & Administrative and support service activities \\
\hline $\mathrm{O}$ & Public administration and defence; compulsory social security \\
\hline $\mathrm{P}$ & Education \\
\hline Q86 & Human health activities \\
\hline Q87_Q88 & Residential care activities; social work activities without accommodation \\
\hline $\mathrm{R}$ & Arts, entertainment and recreation \\
\hline S & Other service activities \\
\hline
\end{tabular}


Table A2. Decision matrix for multi-criteria decision making

\begin{tabular}{|c|c|c|c|c|}
\hline & 1. Mean TE & 2. CV (TE) & $\begin{array}{l}\text { 3. Mean TFP } \\
\text { change }\end{array}$ & 4. CV (TFP) \\
\hline & MAX & MIN & MAX & MIN \\
\hline A & 0.739 & 0.180 & 0.953 & 0.169 \\
\hline $\mathrm{B}$ & 0.775 & 0.160 & 0.957 & 0.094 \\
\hline C10_TO_C12 & 0.665 & 0.124 & 1.013 & 0.081 \\
\hline C13_TO_C15 & 0.676 & 0.171 & 0.985 & 0.087 \\
\hline C16_TO_C18 & 0.666 & 0.095 & 0.999 & 0.101 \\
\hline $\mathrm{C} 20$ & 0.731 & 0.302 & 1.076 & 0.180 \\
\hline $\mathrm{C} 21$ & 1.000 & 0.000 & 1.126 & 0.209 \\
\hline C22_C23 & 0.665 & 0.176 & 1.014 & 0.122 \\
\hline C24_C25 & 0.502 & 0.151 & 1.038 & 0.088 \\
\hline $\mathrm{C} 26$ & 0.407 & 0.249 & 1.054 & 0.144 \\
\hline $\mathrm{C} 27$ & 0.500 & 0.205 & 0.985 & 0.103 \\
\hline $\mathrm{C} 28$ & 0.580 & 0.144 & 1.022 & 0.123 \\
\hline C29_C30 & 0.614 & 0.190 & 1.031 & 0.101 \\
\hline C31_TO_C33 & 0.639 & 0.139 & 1.022 & 0.067 \\
\hline $\mathrm{D}$ & 0.634 & 0.169 & 1.030 & 0.113 \\
\hline $\mathrm{E}$ & 0.419 & 0.062 & 1.017 & 0.073 \\
\hline $\mathrm{F}$ & 0.756 & 0.161 & 0.997 & 0.070 \\
\hline G & 1.000 & 0.000 & 0.986 & 0.038 \\
\hline $\mathrm{H}$ & 0.932 & 0.102 & 1.005 & 0.060 \\
\hline I & 0.844 & 0.066 & 0.992 & 0.036 \\
\hline J58_TO_J60 & 0.585 & 0.115 & 0.967 & 0.098 \\
\hline J61 & 0.951 & 0.079 & 1.000 & 0.076 \\
\hline J62_J63 & 0.741 & 0.165 & 1.005 & 0.177 \\
\hline K & 0.684 & 0.273 & 1.035 & 0.196 \\
\hline $\mathrm{L}$ & 1.000 & 0.000 & 0.994 & 0.050 \\
\hline M69_TO_M71 & 0.956 & 0.067 & 1.022 & 0.118 \\
\hline M72 & 0.945 & 0.149 & 1.003 & 0.339 \\
\hline M73_TO_M75 & 0.833 & 0.094 & 1.035 & 0.059 \\
\hline $\mathrm{N}$ & 0.626 & 0.121 & 1.030 & 0.106 \\
\hline $\mathrm{O}$ & 0.805 & 0.051 & 0.997 & 0.103 \\
\hline $\mathrm{P}$ & 1.000 & 0.000 & 0.998 & 0.095 \\
\hline Q86 & 0.796 & 0.036 & 0.997 & 0.077 \\
\hline Q87_Q88 & 0.633 & 0.230 & 1.018 & 0.135 \\
\hline $\mathrm{R}$ & 0.513 & 0.140 & 0.999 & 0.125 \\
\hline$S$ & 0.857 & 0.167 & 0.951 & 0.169 \\
\hline
\end{tabular}


Tomas BALEŽENTIS is a Junior Research Fellow at the Lithuanian Institute of Agrarian Economics and a PhD student in Vilnius University. He received Student scientific paper award (2011) from the Lithuanian Academy of Sciences and Presidential Scholarship (2012). He has published over 50 peer-reviewed papers on multi-criteria decision making, benchmarking, and quantitative methods.

Algimantas MISIŪNAS, PhD in social sciences, is an Associate Professor at the Department of Quantitative Methods and Modelling in Vilnius University. His scientific interests cover areas of macroeconomic analysis, macroeconomic models, forecasting of economic processes, and informal economy.

Alvydas BALEŽENTIS holds PhD (HP) in Management and Administration and is a Professor at the Institute of Management in Mykolas Romeris University. While working at the Parliament of the Republic of Lithuania, Ministry of Agriculture, and Institute of Agrarian Economics he contributed to creation and fostering of the Lithuanian rural development policy at various levels. His scientific interests cover areas of innovatics, strategic management, sustainable development, and rural development. 